\title{
Erratum: Nuclear deformation in the $A \approx 100$ region: Comparison between new masses and mean-field predictions [Phys. Rev. C 96, 014310 (2017)]
}

A. de Roubin, D. Atanasov, K. Blaum, S. George, F. Herfurth, D. Kisler, M. Kowalska, S. Kreim, D. Lunney, V. Manea, E. Minaya Ramirez, M. Mougeot, D. Neidherr, M. Rosenbusch, L. Schweikhard, A. Welker, F. Wienholtz, R. N. Wolf, and K. Zuber

(Q) (Received 17 April 2018; published 14 May 2018)

DOI: 10.1103/PhysRevC.97.059902

In Fig. 2 of the original article the units of the $x$ axis should be $\approx 24 \mathrm{~ms}$ (not $\approx 2.4 \mathrm{~ms}$ as incorrectly given). The complete Fig. 2 is reprinted here. The results and conclusions of the original article are not affected.

We thank Dr. T. Dickel for bringing the discrepancy in the units to our attention.

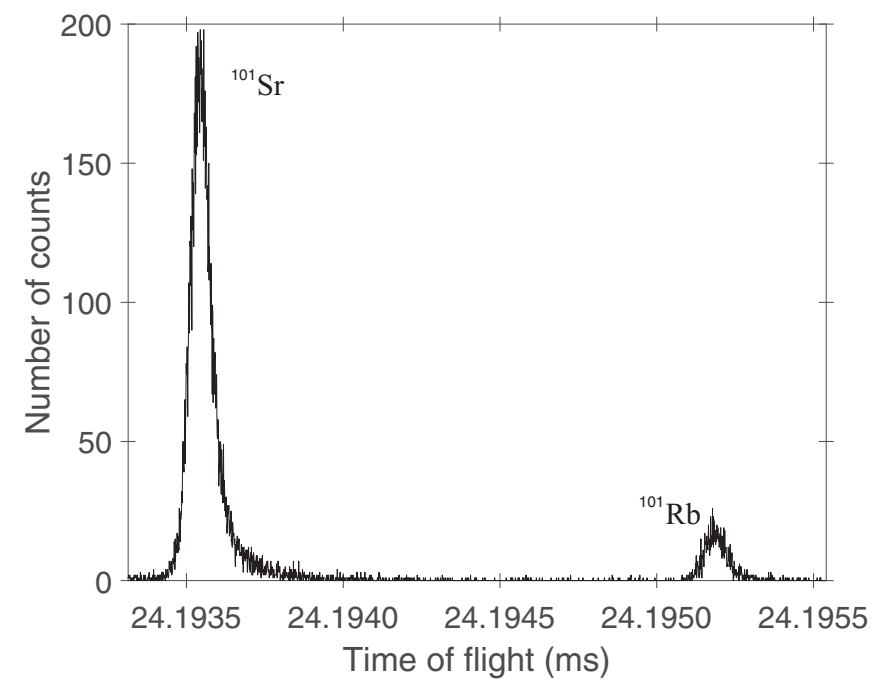

FIG. 2. Time-of-flight (ToF) spectrum of ${ }^{101} \mathrm{Sr}$ and ${ }^{101} \mathrm{Rb}$ after 1000 revolutions inside the multireflection-ToF mass spectrometer.

Published by the American Physical Society under the terms of the Creative Commons Attribution 4.0 International license. Further distribution of this work must maintain attribution to the author(s) and the published article's title, journal citation, and DOI. 